\title{
WorkspaCe ANALYSIS AND Design OF A 3-Dof Micro Parallel Robot
}

\author{
Stan, S.; Maties, V.; BALAN, R.; LAPUSAN, C. \& HANCU, O.
}

Abstract: In this paper a workspace analysis for a three-degree of freedom parallel micro robot is outlined by using optimality criterion of workspace and numerical aspects. We proposed a numerical procedure for determining and evaluating the workspace of the 3-RRR robot architecture. The analysis and algorithm can be used as a design tool to select dimensions, actuators and joints in order to maximize the workspace and improve stiffness within the workspace. A program was created in MATLAB for workspace analysis of 3 DOF parallel robots.

Key words: workspace, optimization, parallel robot, analysis, 3 DOF, singularities
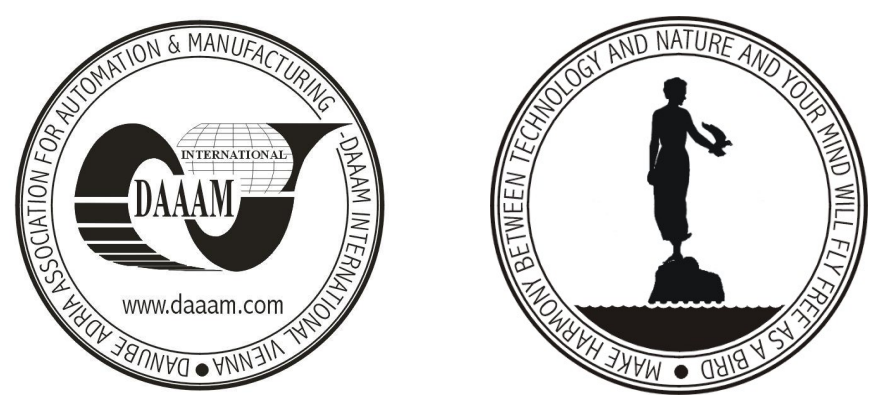

Authors' data: Dr.Ing. Stan, S[ergiu]; PhD Prof. Maties, V[istrian]; PhD Prof. Balan, R[adu]; PhD Student Lapusan, C[iprian]; Ph.D. Hancu, O[limpiu], Technical University of Cluj-Napoca,C. Daicoviciu no. 15, Cluj-Napoca, Romania, sergiustan@ieee.org, Vistrian.Maties@mmfm.utcluj.ro,radubalan@mmfm.utcluj.ro, lapusanciprian@yahoo.com, Olimpiu.Hancu@mmfm.utcluj.ro

This Publication has to be referred as: Stan, S.; Maties, V.; Balan, R.; Lapusan, C. $\&$ Hancu, O. (2007). Workspace Analysis and Design of a 3-Dof Micro Parallel Robot, Chapter 05 in DAAAM International Scientific Book 2007, B. Katalinic (Ed.), Published by DAAAM International, ISBN 3-901509-60-7, ISSN 1726-9687, Vienna, Austria

DOI: $10.2507 /$ daaam.scibook.2007.05 